\title{
Parental Presence Promoted Children Anesthesia Recovery: A Randomized Controlled Study
}

\author{
Rong Hai', Liu Zhang1, Xin Liang1, Gaijing Wang1, Zumei Gao ${ }^{2 *}$ \\ ${ }^{1}$ Department of Medicine, Yangtze University, Jingzhou, China \\ ${ }^{2}$ Nursing Department of First Affiliated Hospital of Yangtze University, Jingzhou, China \\ Email: *1046504865@qq.com
}

How to cite this paper: Hai, R., Zhang, L., Liang, X., Wang, G.J. and Gao, Z.M. (2020) Parental Presence Promoted Children Anesthesia Recovery: A Randomized Controlled Study. Yangtze Medicine, 4, 54-61. https://doi.org/10.4236/ym.2020.41005

Received: October 14, 2019

Accepted: March 27, 2020

Published: March 30, 2020

Copyright $\odot 2020$ by author(s) and Scientific Research Publishing Inc. This work is licensed under the Creative Commons Attribution International License (CC BY 4.0).

http://creativecommons.org/licenses/by/4.0/ (c) (i) Open Access

\begin{abstract}
Objective: There are few studies about restlessness and awakening of children during recovering from anesthesia accompanied by parents. Only one related study was retrieved in China. The purpose of this study is to investigate the effect of awakening, agitation and pain level in children after tonsillectomy accompanied by their parents. Methods: Children who met the inclusion criteria were randomly divided into experimental group and control group according to coin tossing method. There were 30 cases in the experimental group and 32 in the control group. The control group received routine nursing while the experimental group was given parental presence on the basis of routine nursing. Steward awakening score, Pediatric anesthesia emergence delirium (PAED), Scale and FLACC pain assessment scale were used to evaluate the children when they entered anesthesia recovery room and awaked respectively. Results: There was no significant difference in the scoring of three scales between the two groups when they entered anesthesia recovery room $(P>0.05)$. There was significant difference in Steward awakening score and PAED scale between the two groups when they came to recovery room ( $P$ $<0.05)$, but there was no significant difference in FLACC pain score between the two groups $(P>0.05)$. Conclusion: Parental presence can improve the recovery effect and reduce the restlessness of children after operation. Our study suggests that anesthetic children should be accompanied by their parents in the future.
\end{abstract}

\section{Keywords}

Parental Presence, Children, Agitation, Pain

\section{Introduction}

Tonsillectomy is common in pediatric surgery [1] [2], general anesthesia is the 
main method of anesthesia. The common adverse reactions after general anesthesia are agitation and pain, the incidence of restlessness is $10 \%-80 \%$ [3], and the children and the elderly are most likely to take place, the incidence of restlessness of children is $3-8$ times higher than that of adults [4]. Restlessness is a state of separation of consciousness and behavior, although the duration of restlessness is short and self-limited, it increases the risk of falling down from bed, unplanned extubation and delayed discharge, increases the workload of medical staff and the cost of hospitalization [5]. Some studies have reported that there is a certain correlation between post-operative pain and restlessness. They often occur at the same time, and the symptoms are similar and easily confused, which may cause delayed treatment of pain [6].

Children are a special group, the study of postoperative restlessness and pain of them has always been a research hotspot. Surveys have shown that more than $80 \%$ of children in the anesthesia recovery room experienced significant pain [7], more than $28 \%$ of children still feel pain one week after surgery, and affect the growth and development of children and reduce their quality of life [8]. At present, the main ways to reduce postoperative restlessness and relieve postoperative pain are drug and psychological intervention. But drug treatment can prolong the recovery time and increase the occurrence of adverse reactions after operation [9]. Li Lei [10] used preoperative games to reduce the incidence of postoperative agitation. Ruan Fengmei [11] made the children's cooperation increased and adverse reactions decreased by touching them. In Sun Qiaomei's study [12], the use of voice playback after surgery reduced the adverse reactions of children after surgery. However, there are fewer studies about the company of parents. Therefore, this study mainly investigated the effect of awakening, agitation and pain level in children after tonsillectomy accompanied by their parents, aiming at reducing the restlessness and pain level of children after operation, improving the quality of recovery, and providing effective nursing measures for the clinic. The present report is as follows.

\section{Materials and Method}

\subsection{Research Object}

62 cases after tonsillectomy in the anesthesia recovery room from June 2018 to December 2018 in the work were collected. Inclusion criteria: 1) Clinical diagnosis is tonsillitis; 2) Age between 2 - 12 years old; 3) General anesthesia for anesthesia; 4) surgical grading: I - II (according to American Society of Anesthesiologists (ASA) standards); 5) Parents are informed and willing to cooperate. Exclusion criteria: 1) Complicated with other diseases; 2) Accompanied by guardians other than parents during hospitalization. Finally 62 children were included and randomly divided into two groups by coin tossing method, 30 in the experimental group and 32 in the control group. All patients in this study have been informed consent and signed informed consent, and this study was approved by the medical ethics committee of our hospital. 


\subsection{Method}

\subsubsection{Establishment of Research Group}

The research group consists of eight members, including one director nurse, two anesthesiologists, two chief nurses and three nurses. They all work for more than three years, with rich clinical experience and solid theoretical basis. The director nurses are responsible for the quality control of the intervention process and the training for other members of the team, while the other members are responsible for the implementation of specific interventions.

\subsubsection{Intervention Method of Control Group}

1) One day before the operation, the members of the research group made preoperative visits to inform the children and their parents about the time of preoperative fasting and the possible situation of the children during the anesthesia process and the methods needed to cooperate.

2) Introduce the specific content of this study, sign the informed consent. Collect the general information of the children for baseline assessment.

3) On operative day, the parents accompanied the children into the anesthesia induction room and cooperated with the anesthesiologist. After the children lost consciousness and the anesthesia was stable, the family members left.

4) After the operation, the children were sent to the anesthesia recovery room and given routine nurse (oxygen inhalation, atomization and ECG monitoring). The research group observed the objective condition of the children and filled out the scoring forms truthfully.

5) After the recovery of the children, the responsible nurses give them routine care and psychological comfort. According to the children's muscular tension, coordination degree and autonomous consciousness, the anesthesiologists and responsible nurses will escort the children back to the ward.

\subsubsection{Intervention Methods of Experimental Group}

On the basis of routine nursing of the control group, the experimental group received parental presence. The research group informed the patient to enter the anesthesia recovery room after the operation, they were instructed by the responsible nurses to carry out hand hygiene treatment, change shoes, wear masks and hats, and wear isolation clothes. They waited in the waiting room for the children to enter the anesthesia recovery room. After the children were sent to the anesthesia recovery room, the parents can hold their children, call his name, comfort the patient, so that the child can feel his parents around.

\subsubsection{Research Tools}

\section{1) The general information questionnaire}

It was designed by the members of the research group, including age, gender, weight, first operation and so on.

\section{2) Steward awakening score}

Steward Awakening Score [13] is one of the most commonly used scale in anesthesia recovery room to determine whether children can leave the recovery 
room or not. The scale is mainly judged from three dimensions: consciousness, respiratory tract patency and autonomous activity. Each dimension is three-level score ( 0 - 2 point) and the total score is 6 points, children can leave the recovery room while their score is more than 4 points.

\section{3) PAED Scale}

PAED (Pediatric anesthesia emergence delirium) scale was used to assess restlessness in children during anesthesia recovery, developed by professor Sikich $\mathrm{N}$ in 2004 [14] [15]. The scale judging from the following 5 dimensions: eye contact, purposeful sexual behavior, environmental alertness, anxiety, crying, every dimension has a five-grade score of $0-4$ points, with a total score of up to 20 points. We give step-down scores according to their severity $(4=$ not at all, $3=$ just a little, $2=$ quite a bit, $1=$ very much, $0=$ extremely) in the first three dimensions, and step-up scores $(0=$ not at all, $1=$ just a little, $2=$ quite a bit, $3=$ very much, 4 = extremely) in the following two dimensions. The sum of scores in the five dimensions indicates the severity of agitation, with bigger values representing more serous condition. The internal consistency of the PAED scale was 0.89 , the reliability was 0.84 and the sensitivity was 0.64 [15].

\section{4) FLACC pain assessment scale}

FLACC (Face, Legs, Activity, Crying, Consolability) Pain Assessment Scale [16] is an effective method for children's postoperative pain assessment, including 5 dimensions: facial, leg, autonomous movement, crying and comfort, each dimension has a three-level score of 0 - 2 points, with a total score of up to 10 points. The higher the score, the more severe the pain.

\subsubsection{Data Collection Method}

One day before the operation, we collected general information of the two groups. The Steward Recovery Score, Quantitative Restlessness Score Scale and FLACC Pain Assessment Scale were collected by the group members on the day of operation, and filled according to the objective condition of the children after operation truthfully. All the children and their parents cooperated well without dropping out. The validity rate of the questionnaire was $100 \%$.

\subsubsection{Quality Control}

Before the clinical intervention, the training of group members needs to be skilled in the whole intervention process, the preoperative propaganda content, matters need to pay attention, the specific implementation of the questionnaire and so on. Unified and easy-to-understand guidance should be adopted to educate children and their parents so as to minimize the deviation in intervention and data collection and ensure the correctness of the research. In the process of data collection, timely verification should be made to reduce omissions. Data are input in pairs and checked.

\subsubsection{Statistical Method}

SPSS 22.0 software was used for statistical analysis. Weighted Mean Difference (MD) was used for measurement data $(\bar{x} \pm s)$ while count data were expressed 
as number (\%) and independent sample t-test was used for measuring data and chi-square test $\left(\mathrm{X}^{2}\right)$ was used for counting data. $P<0.05$ was considered statistically significant.

\section{Results}

\subsection{General Data Comparison of Two Groups}

The experimental group consisted of 19 males and 11 females, age (6.90 \pm 2.12 ) years, weight $(28.08 \pm 10.23) \mathrm{Kg}$ and $25(83.33 \%)$ children undergoing the first operation. The control group consisted of 19 males and 13 females, age (7.00 \pm $2.36)$ years, weight $(26.59 \pm 8.70) \mathrm{Kg}$ and 29 (90.62\%) children undergoing the first operation. There was no significant difference in gender, age, weight, whether the first operation was performed and operative duration between the two groups $(P>0.05)$, which was comparable (Table 1$)$.

\subsection{Comparison of Awakening, Restlessness and Pain Scores between the Two Groups}

There was no significant difference in Steward awakening score, PAED scale score and FLACC pain score between the two groups before they were sent to the anesthesia recovery room $(P>0.05)$. There were significant differences in Steward awakening score and PAED scale score between the two groups when they wake up $(P<0.05)$, there was no significant difference in FLACC pain score between the two groups $(P>0.05)$ (Table 2).

Table 1. General data comparison of two groups.

\begin{tabular}{|c|c|c|c|c|c|c|c|}
\hline & \multirow{2}{*}{ Cases } & \multicolumn{2}{|c|}{ Gender (\%) } & Age & Weight & \multirow{2}{*}{$\begin{array}{c}\text { First operation } \\
(\%)\end{array}$} & \multirow{2}{*}{$\begin{array}{l}\text { Operative duration } \\
\quad(\min , \bar{x} \pm \mathrm{s})\end{array}$} \\
\hline & & Male & Female & (years, $\bar{x} \pm s$ ) & $\left(\begin{array}{ll}\mathrm{Kg}, & \bar{x} \quad \pm \mathrm{s})\end{array}\right.$ & & \\
\hline $\mathrm{EP}$ & 30 & 19 & 11 & $6.90 \pm 2.12$ & $28.08 \pm 10.23$ & $25(83.33)$ & $48.13 \pm 19.12$ \\
\hline $\mathrm{CP}$ & 32 & 19 & 13 & $7.00 \pm 2.36$ & $26.59 \pm 8.70$ & $29(90.62)$ & $50.09 \pm 21.19$ \\
\hline Statistical value & & \multicolumn{2}{|c|}{0.1022} & -0.1751 & 0.6181 & 0.7332 & -0.3821 \\
\hline$P$ value & & \multicolumn{2}{|c|}{0.749} & 0.861 & 0.541 & 0.392 & 0.703 \\
\hline
\end{tabular}

PS: 1 : $\mathrm{t}$ value; 2 : $\mathrm{X}^{2}$ value.

Table 2. Comparison of awakening, restlessness and pain scores.

\begin{tabular}{|c|c|c|c|c|}
\hline & Cases & Steward Score $(\bar{x} \pm s)$ & PAED Score $(\bar{x} \pm s)$ & $\operatorname{FLACC}$ Score $\left(\begin{array}{ll}\bar{X} & \pm s\end{array}\right)$ \\
\hline \multicolumn{5}{|c|}{ Entry the recovery room } \\
\hline $\mathrm{EP}$ & 30 & $3.57 \pm 0.72$ & $11.53 \pm 1.16$ & $1.70 \pm 0.46$ \\
\hline $\mathrm{CP}$ & 32 & $3.38 \pm 0.75$ & $11.63 \pm 1.10$ & $1.78 \pm 0.49$ \\
\hline $\mathrm{t}$ value & & 1.019 & -0.318 & -0.667 \\
\hline$P$ value & & 0.312 & 0.752 & 0.506 \\
\hline \multicolumn{5}{|l|}{ Awake } \\
\hline EP & 30 & $5.60 \pm 0.62$ & $4.97 \pm 1.77$ & $1.50 \pm 0.57$ \\
\hline $\mathrm{CP}$ & 32 & $5.00 \pm 0.44$ & $8.13 \pm 2.12$ & $1.56 \pm 0.50$ \\
\hline $\mathrm{t}$ value & & 4.410 & -6.341 & -0.457 \\
\hline$P$ value & & 0.000 & 0.000 & 0.651 \\
\hline
\end{tabular}




\section{Discussion}

The results of this study showed that there were significant differences in Steward awakening score and PAED scale score between the two groups $(P<0.05)$, indicating that parental presence could significantly reduce the restlessness of children and improve the recovery effect, which was consistent with the results of Han Ailing's study [17]. Restlessness is a common adverse reaction after operation, which not only affects the effect of operation, but also increases the workload of medical staff, and even causes serious consequences, such as unplanned extubation, bleeding, asphyxia caused by unconscious activities and crying, threatening the life safety of children. Children's physical and mental is in the stage of development and their cognitive function is poor, when they stimulated by strong stressors, suah as operation and pain, may cause mental trauma and cognitive impairment [18]. At present, analgesics and sedatives are mainly used for the treatment of restlessness and pain. Some studies [9] show that some analgesics can relieve the pain after operation, but have the risk of bronchospasm, respiratory depression, nausea and vomiting, and prolong the recovery time. Some studies have shown that children depend heavily on their parents [18]. Parental presence can reduce salivary cortisol level [19], alleviate anxiety level of children, reduce the incidence of post-operative agitation and adverse reactions, and can pass the recovery period smoothly. On the contrary, without parental presence, children cannot cooperate or even conflict with the treatment, and not be able to achieve a good recovery effect.

However, there was no significant difference in FLACC pain score between the two groups $(P>0.05)$. Compared with recent studies [7] [20], it was found that the effect of parental presence on pain relief in children during recovery period is not obvious, which may be caused by diseases. Jenkins and Bai Xue et al. [7] [20] did not have a unified disease, the subjects of this study were all after tonsillectomy. Because of the dense distribution of blood vessels and nerves in the oropharynx, speaking and swallowing can cause muscle movement in the oropharynx, stimulate the surgical site and cause obvious pain after operation. In addition, it's also possible that parental concerns are different. There was study [21] indicated that parents pay attention to the pain of the operation and use the tone of apology to communicate with the children, which makes the pain more obvious after the operation.

In the process of the study, it was found that the parents were worried about the operation because of the age of children are younger. It was also possible that psychological quality of some parents is relatively weak and they lack knowledge about diseases, some common problems after the operation, such as crying and restlessness of the children, would lead to parents' anxiety, and then affect the children, such a vicious circle. Therefore, it is particularly important to evaluate the psychological quality of the parents of the children, and suggest the parents with better psychological quality to parental presence. Secondly, the medical staff should introduce the environment, equipment to parents so that they can 
be fully prepared to relieve the influence of unfamiliar environment on them. Finally, the medical staff should guide parents to correctly identify the abnormal situation, relive their tension, improve the relationship between nurses and patients, and reduce medical disputes. The children's condition in the anesthesia recovery room is dynamic, all of us should always be alert to the change of the children's condition. Whether accompanied by parents or not, anesthesia nurses should always monitor the vital signs and pulse oxygen of the children to ensure the children's respiratory tract is unobstructed and the safety of the children.

There are limitations in this study: firstly, there is a large difference in the age of the children included, which leads to a large difference in their psychological, physiological and cognitive aspects. Then, the number of samples included in this study was small. Lastly, only the state of anesthesia room was studied and the observation time was short.

\section{Conclusion}

This study confirmed that the recovery time of children after general anesthesia can be reduced by parental presence. Parental presence can reduce restlessness and improve the quality of recovery. In addition, due to the limitations of this study, it is suggested that future research should expand the sample size, select appropriate research samples, control the age and disease, and extend the observation time.

\section{Conflicts of Interest}

The authors declare no conflicts of interest regarding the publication of this paper.

\section{References}

[1] Kou, Y.F., Mitchell, R.B. and Johnson, R.F. (2019) A Cross-Sectional Analysis of Pediatric Ambulatory Tonsillectomy Surgery in the United States. Otolaryngology. Head and Neck Surgery, 161, 699-704.

[2] Hall, M.J., Schwartzman, A., Zhang, J., et al. (2017) Ambulatory Surgery Data from Hospitals and Ambulatory Surgery Centers: United States, 2010. National Health Statistics Reports, No. 102, 1-15.

[3] Zhang, H., Fan, Q., Zhang, J., et al. (2019) Effect of Ultrasound-Guided Lumbar Plexus Block on Emergence Agitation in Children Undergoing Hip Surgery: Study Protocol for a Randomized Controlled Trial. Trials, 20, 22-30. https://doi.org/10.1186/s13063-018-3140-3

[4] In, W., Kim, Y.M., Kim, H.S., et al. (2019) The Effect of a Parental Visitation Program on Emergence Delirium among Postoperative Children in the PACU. Journal of PeriAnesthesia Nursing, 34, 108-116. https://doi.org/10.1016/j.jopan.2018.04.003

[5] Moore, A.D. and Anghelescu, D.L. (2017) Emergence Delirium in Pediatric Anesthesia. Paediatr Drugs, 19, 11-20. https://doi.org/10.1007/s40272-016-0201-5

[6] Somaini, M., Engelhardt, T., Fumagalli, R., et al. (2016) Emergence Delirium or Pain after Anaesthesia-How to Distinguish between the Two in Young Children: A Retrospective Analysis of Observational Studies. British Journal of Anaesthesia, 116, 
377-383. https://doi.org/10.1093/bja/aev552

[7] Jenkins, B.N., Fortier, M.A., Stevenson, R., et al. (2019) Changing Healthcare Provider and Parent Behaviors in the Pediatric Post-Anesthesia-Care-Unit to Reduce Child Pain: Nurse and Parent Training in Postoperative Stress. Paediatric Anaesthesia, 29, 730-737. https://doi.org/10.1111/pan.13649

[8] Brown, R., Fortier, M.A., Zolghadr, S., et al. (2016)Postoperative Pain Management in Children of Hispanic Origin: A Descriptive Cohort Study. Anesthesia \& Analgesia, 122, 497-502. https://doi.org/10.1213/ANE.0000000000001042

[9] Jalili, S., Esmaeeili, A., Kamali, K., et al. (2019) Comparison of Effects of Propofol and Ketofol (Ketamine-Propofol Mixture) on Emergence Agitation in Children Undergoing Tonsillectomy. African Health Sciences, 19, 1736-1744. https://doi.org/10.4314/ahs.v19i1.50

[10] Li, L. and Li, X.M. (2019) The Effect of the Blindfolded Test on Relieving Emergence Agitation of Children after Strabismus Surgery. World Latest Medicine Information (Electronic Version), 19, 23-28.

[11] Ruan, F.M. (2012) Touch Care in Ophthalmological Pediatric General Anesthesia. Shandong Medical College School Newspaper, 34, 290-291.

[12] Sun, Q.M. (2018) The Effect of Playing Parental Voice on Recovery Quality of Children with General Anesthesia during Recovery Period. Shandong University, Jinan.

[13] Guo, X.B. (2017) Comparison of the Effects of Two Resuscitation Scoring Methods on Resuscitation after General Anesthesia. China Medical Engineering, 25, 43-45.

[14] Ringblom, J., Wahlin, I. and Proczkowska, M. (2018) A Psychometric Evaluation of the Pediatric Anesthesia Emergence Delirium Scale. Pediatric Anesthesia, 28, 332-337. https://doi.org/10.1111/pan.13348

[15] Sikich, N. and Lerman, J. (2004) Development and Psychometric Evaluation of the Pediatric Anesthesia Emergence Delirium Scale. Anesthesiology, 100, 1138-1145. https://doi.org/10.1097/00000542-200405000-00015

[16] Crellin, D.J., Harrison, D., Santamaria, N., et al. (2015) Systematic Review of the Face, Legs, Activity, Cry and Consolability Scale for Assessing Pain in Infants and Children: Is It Reliable, Valid, and Feasible for Use? Pain, 156, 2132-2151. https://doi.org/10.1097/j.pain.0000000000000305

[17] Han, A.L. (2017) Application Analysis of Accompanied by Family Members on Restlessness during Awakening Period of General Anesthesia in Children. Journal of Changzhi Medical College, 31, 233-234.

[18] Li, Y. and Ma, X.B. (2018) Research Progress of Psychological Nursing Applied to Anesthesia Induction in Children. Chinese General Practice Nursing, 16, 4253-4255.

[19] Ozdogan, H.K., Cetinalp, S., Kuran, G., et al. (2017) The Effects of Maternal Presence during Anesthesia Induction on Salivary Cortisol Levels in Children Undergoing Tonsillectomy and/or Adenoidectomy. Journal of Clinical Anesthesia, 39, 64-66. https://doi.org/10.1016/j.jclinane.2017.03.001

[20] Bai, X. and Du, Y.J. (2018) Influence of Parental Companionship during the Emergence and Recovery Phase on Children's Anxiety and Agitation. Journal of Nursing Science, 33, 38-40.

[21] Chorney, J.M., Tan, E.T. and Kain, Z.N. (2013) Adult-Child Interactions in the Post-Anesthesia Care Unit: Behavior Matters. Anesthesiology, 118, 834-841. https://doi.org/10.1097/ALN.0b013e31827e501b 